\title{
Method of aberration compensation in sapphire optical disks for the long term data storage
}

\author{
V.V.Petrov, V.P.Semynozhenko ${ }^{*}$, V.M.Puzikov", A.A.Kryuchyn, \\ A.S.Lapchuk, Ye.M.Morozov, Y.O.Borodin, \\ O.V.Shyhovets, S.M.Shanoylo \\ Institute for Information Recording, National Academy of Sciences of \\ Ukraine, 2 Shpak Str., 03113 Kyiv, Ukraine \\ "STC "Institute for Single Crystals", National Academy of Sciences of \\ Ukraine, 60 Lenin Ave., 61001 Kharkiv, Ukraine
}

Received January 22, 2014

\begin{abstract}
One of the actual problems today is creation of the long term data storage systems. This paper presents the research results that allow implementing technical solution proposed by the authors of this work a few years ago to create the long term storage optical discs based on single crystal sapphire. It is shown that the problem of data reading through the anisotropic substrate can be solved by using the single crystal optical compensating elements. The experimental results confirm an efficiency of the proposed method of aberration compensation for the long term data storage sapphire media.
\end{abstract}

Задача создания систем долговременного хранения данных является одной из актуальных проблем современности. В работе представлены результаты исследований, которые позволяют реализовать техническое решение, предложенное авторами несколько лет назад, по созданию оптических дисков для долговременного хранения данных на основе монокристаллического сапфира. Показано, что проблема считывания данных через подложку из анизотропного материала может быть решена с использованием оптических монокристаллических компенсирующих элементов. Представлены результаты экспериментальных исследований, подтверждающие эффективность предложенного метода компенсации.

Метод компенсацї̈ аберацій в сапфіровому диску для довготривалого зберігання даних. В.В.Петров, В.П.Семиноженко, В.М.Пузіков, А.А.Крючин, А.С.Лапчук, С.М.Моро зов, Ю.О.Бородін, О.В.Шиховець, С.М.ШШанойло.

Задача створення систем довготривалого зберігання даних є однією з актуальних проблем сучасності. В роботі представлено результати досліджень, які дозволяють реалізувати технічне рішення, яке було запропоноване авторами декілька років тому назад, задля створення оптичних дисків для довготривалого зберігання даних на основі монокристалічного сапфіру. Показано, що проблема зчитування даних через підкладку з анізотропного матеріалу може бути вирішена за допомогою використання оптичних монокристалічних компенсаційних елементів. Представлено результати експериментальних досліджень, які підтверджують ефективність запропонованого методу компенсаціï. 


\section{Introduction}

Optical discs are widely used in data storage for storage, dissemination and archiving the digital information. In nowadays application of the optical disk for the long-term archival data storage attracts a particular special interest. However, the existing optical discs can't provide the required level of reliability and data storage time due to low stability of a polycarbonate substrate [1], and insufficiently strong adhesion of a metal layer with the polycarbonate substrate. To solve the long-term storage problem it was proposed to use a variety of technical solutions, which are based on using the highly stable materials for recording media and media substrate.

In optical write-once discs for the longterm storage (storage period is 150160 years), so-called M-disks it was offered to use cermets as the recording medium [2]. It is proposed to use a borosilicate glass with the relief microstructure on the surface obtained by ion-beam etching [3] and refractory metals such as tungsten and platinum. Silicon nitride is proposed to seal tungsten discs [4], and information from platinum substrates read through the sapphire windows [5]. To create the optical media for the long term storage is also proposed to use quartz substrates [6].

For the long-term data storage it is appropriate to apply a substrate from highly stable single crystal materials [7]. However, the most of single crystal materials have a significant anisotropy which manifests itself in optics as birefringence. The birefringence causes aberration distortion of scanning beam as it passes through the optical disc due to difference in the paths of light rays with different polarization. Presence of the polarization aberration makes it impossible to use standard reading systems for reproducing information from an optical disc with the single crystal substrate. Therefore, use of single crystal materials as substrates of optical discs for the longterm data storage requires optical system modification to compensate the arising geometric aberrations. Investigation of existing highly stable uniaxial single crystal materials showed that the best material for the optical disk substrate is leucosapphire [7] since it has high chemical stability; its wear resistance is 8 times more than of steel, sapphire is thermally stable up to $1600^{\circ} \mathrm{C}$ and it is optically transparent in the range from $0.17 \mu \mathrm{m}$ to $5.5 \mu \mathrm{m}$ [8]. In optical recording

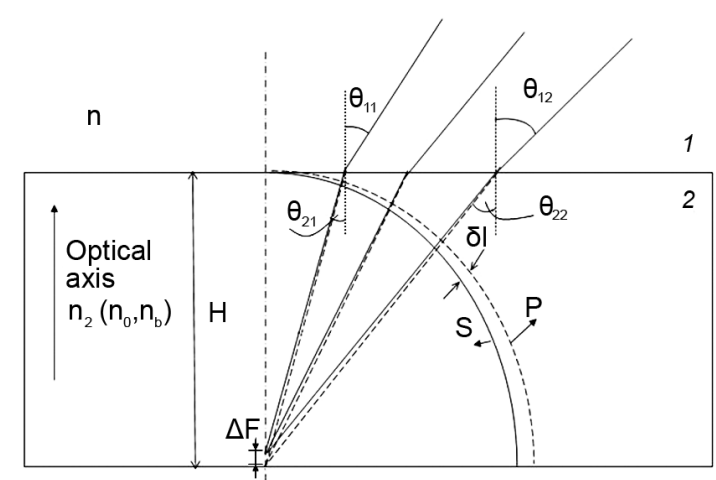

Fig. 1. Propagation of laser focused beam through monocrystal substrate.

systems only optical uniaxial birefringent discs can be applied, the optical axis of which is orthogonal to the disk surface.

This paper describes aberration compensations of the information reading system from an optical disc substrate which is made of the uniaxial optical single crystal material, the optical axis of which is orthogonal to the substrate surface. The developed method of aberration compensation was applied to the long term sapphire optical disc and the basic parameters of the optical system for reading information and optical disk are evaluated. Experimental verification of the developed method was carried out.

\section{Theoretical background and calculations}

\subsection{Propagation of laser focused beam through anisotropic medium}

Let us consider the propagation of a focused laser beam through the single crystal substrate (Fig. 1). We assume that 1) the crystal optical axis is oriented orthogonally to the substrate surface and 2) reading and recording processes are performed using standard objective lens of optical device of specified format (CD, DVD and BluRay). These standard optical objective lenses compensate spherical aberration of the substrates of the standard format disk, which do not have optical anisotropy.

Let us consider difference between the optical paths for $s$ - and $p$-polarized light beams, the value of which characterizes the amount of aberration caused by birefringence. The aberration is due to the fact that at obliquely incident on the disk $s$ - and $p$ polarized beams have different phase velocity. The value of difference between the op- 
tical paths of $s$ - and $p$-polarized light (polarization aberration) will increase with increasing an angle of the beam spreading $\theta_{11}$. Another feature of the beam focused into birefringent plate is that the division of light on $s$ - and p-polarization is local. That is the amplitudes of the $s$ - and $p$-polarizations are functions of coordinates on the lens surface and polarization of the laser beam. Incident optical radiation with fixed polarization may be either $s$ - or $p$-polarized depending on place where it falls onto the lens (relative to the lens surface). In this connection arising aberrations can be compensated only by optical elements which are sensitive to the light polarization, that is, by elements with the optical anisotropy.

Dispersion of anomalous beam ( $p$-polarized) can be written as [9]:

$$
n_{p}=\frac{n_{0}}{\sqrt{1+\frac{\left(n_{o}^{2}-n_{e}^{2}\right)}{n_{e}^{2}} \sin ^{2} \theta_{21}}}
$$

where $n_{o}$ is index of refraction of the ordinary ray, $n_{e}$ is index of refraction of the extraordinary ray (see Fig. 1).

Normal beam has no dispersion and therefore:

$$
n_{s}=n_{o}
$$

Difference between optical paths of $s$ - and $p$-polarized beams, as it is shown in Fig. 1, can be written as [10]:

$$
\begin{gathered}
\Delta \Phi_{p}=\frac{H}{\cos \theta_{21}}\left(k_{1}-k_{2}\right)= \\
=\frac{2 \pi}{\lambda} H \frac{\sin ^{2} \theta_{21}}{\cos \theta_{21}} \Delta n= \\
=\frac{2 \pi}{\lambda} H \frac{\frac{\sin ^{2} \theta_{21}}{\sin ^{2} \theta_{22}}}{\sqrt{1-\frac{\sin ^{2} \theta_{21}}{\sin ^{2} \theta_{22}} \sin ^{2} \theta_{22}}} \sin ^{2} \theta_{22} \Delta n= \\
=\frac{2 \pi}{\lambda} H \frac{x^{2}}{\sqrt{1-x^{2}\left(\frac{N A}{n_{2}}\right)^{2}}\left(\frac{N A}{n_{2}}\right)^{2} \Delta n=} \\
=\frac{2 \pi}{\lambda} H\left[\left(\frac{N A}{n_{2}} x\right)^{2}+\frac{1}{2}\left(\frac{N A}{n_{2}} x\right)^{4}+\frac{3}{8}\left(\frac{N A}{n_{2}} x\right)^{6}+\ldots\right] \Delta n
\end{gathered}
$$

where $k_{1}$ is wave number of the extraordinary ray, $k_{2}$ is wave number of the ordinary ray, $H$ is thickness of the substrate, $\Delta n$ is difference in the refractive indexes of the
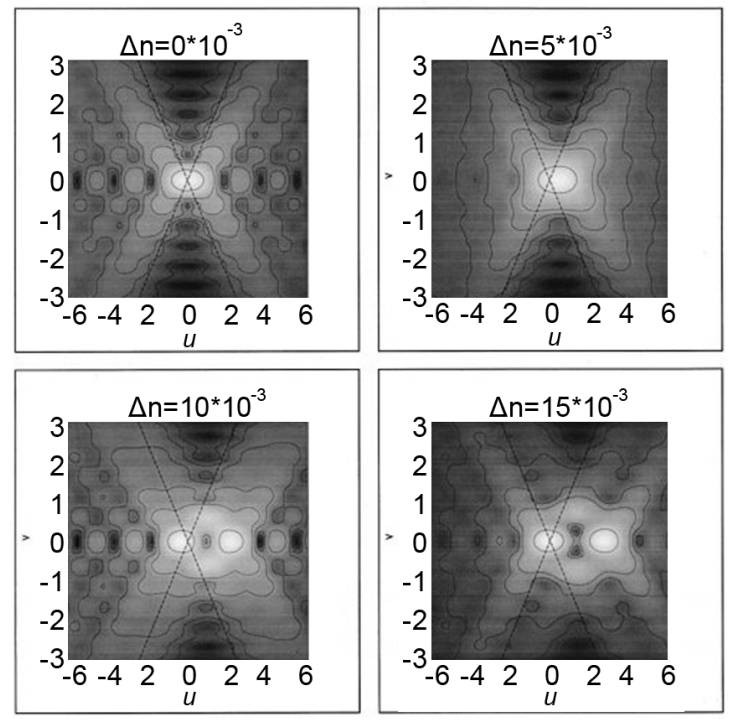

Fig. 2. Laser beam intensity in the meridional plane of anisotropy.

ordinary and extraordinary rays in the substrate material $\left(\Delta n=n_{o}-n_{e}\right), N A$ is numerical aperture $\left(N A=n_{2} \cdot \sin \theta_{22}\right), n_{2}$ is refractive index of the substrate, $x=$ $\sin \theta_{21} / \sin \theta_{22}$.

Formula (3) shows that the phase distortion has complex dependence on angle of incidence and represents a superposition of astigmatism and spherical aberrations of the different orders. The first term is the most significant in formula (3). It determines the difference in focal length of $s$ - and $p$-polarized light beams (astigmatism) that leads to the two focused light spots. From Eq. (3) follows that the distance between the centers of the light spots of $s$ - and $p$-polarized beams is:

$$
\Delta F=2 H \Delta n / n_{2} \text {. }
$$

Fig. 2 shows the laser beam intensity distribution in the meridional plane for different values of anisotropy [10]. From these graphs we can see that small anisotropy blurs light spot and its blurriness increases with an increase of anisotropy and thickness of the substrate. For the anisotropy large values, when the distance between the centers of the spots is comparable to the depth of focus ( $\Delta F \geq \lambda n_{2} / N A^{2}$ ), there are two light spots formed by the light beams with different polarization.

To determine the anisotropy allowable values for the sapphire substrate $\left(\Delta n_{o}=\left|n_{e}-n_{o}\right|\right)$ at which the focused laser beam is diffraction limited (a necessary condition for the optical system of optical information re- 
V.V.Petrov et al. / Method of aberration compensation...

Table 1. The permissible level of anisotropy for different optical disc format

\begin{tabular}{|c|c|c|c|c|c|c||}
\hline $\begin{array}{c}\text { Type of } \\
\text { media }\end{array}$ & $\lambda$ & $N A$ & $n_{o}$ & $\max \Delta n_{o}$ & $10 \% \max \Delta n_{o}$ & $\begin{array}{c}\Delta n_{o} \text { for } \\
\text { sapphire }\end{array}$ \\
\hline CD & 780 & 0.45 & 1.78 & $2.5 \cdot 10^{-3}$ & $7.3 \cdot 10^{-4}$ & $8 \cdot 10^{-3}$ \\
DVD & 650 & 0.6 & 1.78 & $2.4 \cdot 10^{-3}$ & $7.1 \cdot 10^{-4}$ & $8 \cdot 10^{-3}$ \\
BD & 400 & 0.85 & 1.78 & $2.7 \cdot 10^{-3}$ & $7.9 \cdot 10^{-4}$ & $8 \cdot 10^{-3}$ \\
CD/BD & 400 & 0.26 & 1.78 & $3.1 \cdot 10^{-3}$ & $8.8 \cdot 10^{-4}$ & $8 \cdot 10^{-3}$ \\
\hline
\end{tabular}

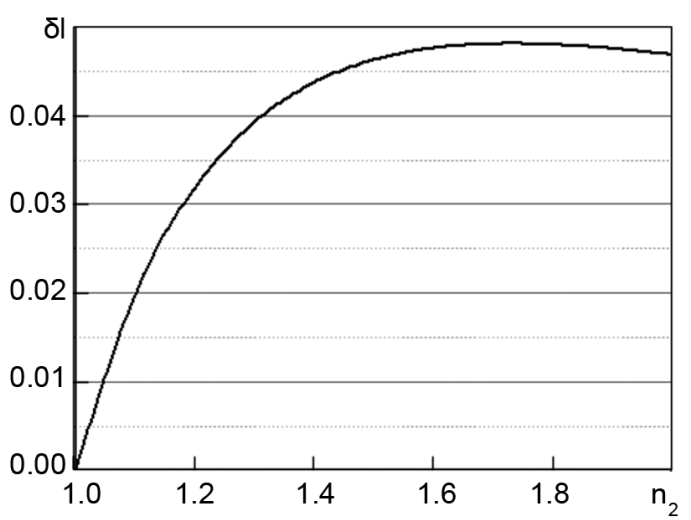

Fig. 3. Dependence of spherical aberration $\delta l$ on the refractive index $n_{2}$.

cording device) the dependence of the light intensity at the center of light spot on the magnitude of $\Delta n$ for optical disc CD, DVD and BD formats was simulated. Strehl ratio was chosen as a criterion of diffraction limited optical system. We also evaluate possibility of using the optical system with laser having wavelength of $\lambda=405 \mathrm{~nm}$ and numerical aperture of $N A=0.26$ for reading data in $\mathrm{CD}$ format through the sapphire substrate. Simulation results are shown in Table 1.

In Table $1 \max \Delta n_{o}$ is maximum possible deviation of the refractive index to have diffraction limited optical system. From the presented data it is clear that any formats can not use sapphire substrate having an orthogonal orientation of the optical axis to the surface of the disc directly without additional compensation system, because this leads to aberrations which greatly exceed the permissible value max $\Delta n_{o}$.

Also spherical aberration occurs at the propagation of a focused laser beam through the optical disc due to the difference in the refractive indexes of sapphire and polycarbonate. It is known that the plane-parallel layer introduces spherical aberration into the passing therethrough it light beam. The amount of spherical aberration can be calculated by the formula [9]:

$$
\frac{\delta l_{1}}{\lambda}=\frac{n_{o}^{2}-1}{8 n_{o}^{3}} N A^{4} \frac{H}{\lambda} r^{4} .
$$

From equation (5) one can see that the magnitude of aberration depends on the refractive index as a function $\left(n_{o}{ }^{2}-1\right) / 8 n_{o}{ }^{3}$, whose graph is shown in Fig. 3 .

Since sapphire and polycarbonate have different indexes of refraction $\left(n_{o}\right.$ spf $=$ $1.78038, n_{o} p l c=1.58$ ) then the sapphire disk should have different from polycarbonate disk thickness to have the same spherical aberration (for using the standard optical system for information reading). From the graph it can be seen that at $n_{2}=1.7$ the spherical aberration has broad maximum and weakly depends on the refractive index and so one can be expected only slight differences in the magnitudes of spherical aberration for the two disks with the same thickness.

\subsection{Method for compensating aberrations of focused laser beam}

Let us consider possibility of compensation of the aberration due to anisotropic disc medium (uniaxial crystal with an orthogonal orientation of the optical axis to the disk surface) by an additional layer of uniaxial material and having vertical orientation of the optical axis. The resulting aberration is total aberration of each layer and therefore may be expressed from (3) as follows:

$$
\begin{gathered}
\Delta \Phi=\Delta \Phi_{1}+\Delta \Phi_{2}= \\
=k x^{2} N A^{2}\left(\frac{H_{1}}{n_{1}^{2}} \Delta n_{1}+\frac{H_{2}}{n_{2}^{2}} \Delta n_{2}+N A^{2}\left(\frac{H_{1}}{n_{1}^{4}} \Delta n_{1}+\frac{H_{2}}{n_{2}^{4}} \Delta n_{2}\right)+\ldots\right),
\end{gathered}
$$

where $H_{1}$ and $n_{1}$ are thickness and refractive index of the additional layer respectively, $\mathrm{H}_{2}$ and $n_{2}$ are thickness and refractive index of the disc substrate respectively. From formula (7) you can see that in the case of using the standard objective lens the 

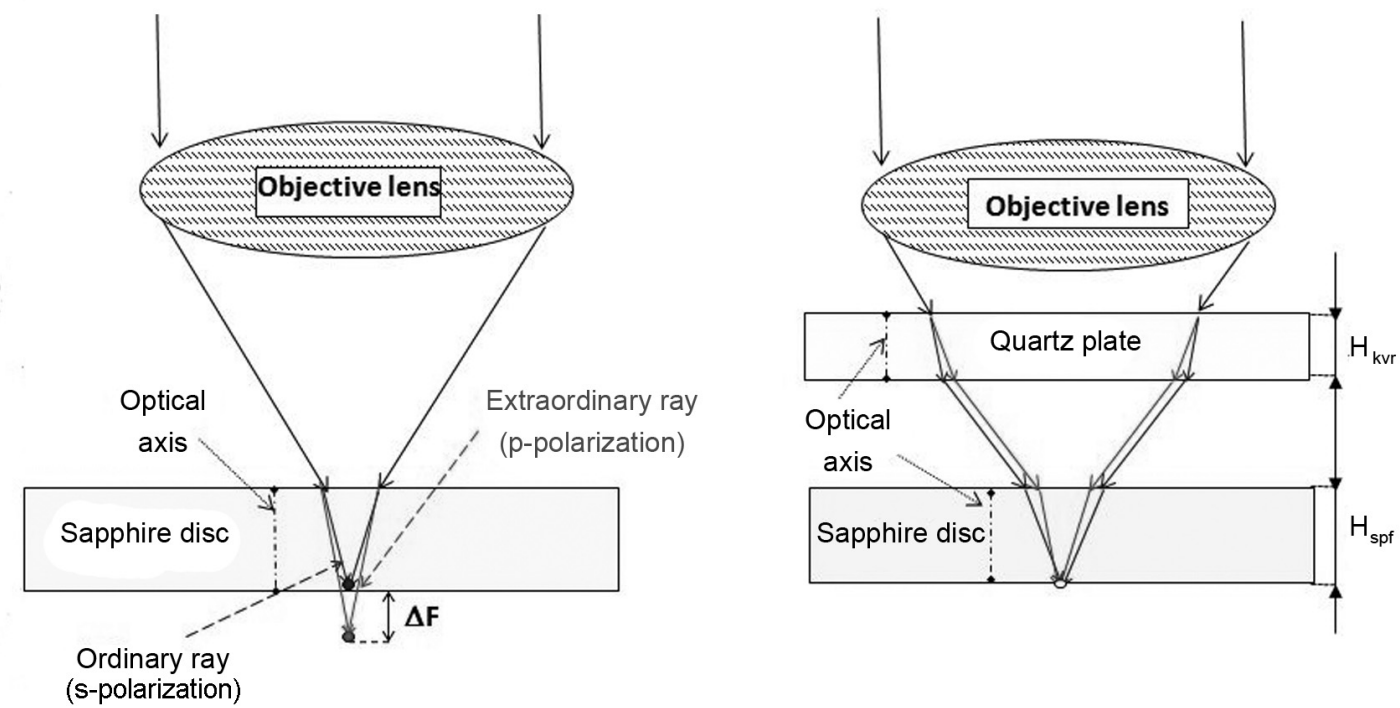

Fig. 4. Schematic representation of the ordinary and extraordinary rays propagation.

substrate aberration can be considerably compensated if the additional layer has refractive index value $n_{o}, n_{e}$ inverse to the refractive indexes of sapphire. If substrate material of the optical disc and material of the additional layer are close in value of the index of refraction for the ordinary ray $n_{o}$, you can actually achieve total compensation for aberration caused by the anisotropy of the disk substrate. Otherwise, the compensation will be partial. Investigation of available transparent uniaxial optical crystals showed that the best material for compensating of the sapphire substrate aberrations is quartz, which has the following indexes of refraction: $n_{o}=1.5443, n_{e}=1.5534$. Schematic representation of the compensation method of aberrations is shown in Fig. 4 .

In the case of using the standard optical information reading system (information is recorded in CD-format) the relative value of spherical aberration of sapphire disc with quartz compensator having the same thickness as polycarbonate layer can be calculated by follows formula:

$$
\frac{\frac{\delta l_{s p f}}{\lambda}-\frac{\delta l_{p l c}}{\lambda}}{\frac{\delta l_{1}}{\lambda}}=0.0073,
$$

from which is clear that difference is small and the sum of quartz and sapphire disk thicknesses should be equal to thickness of polycarbonate disk. Table 2 shows the permissible value of thickness of substrate for different disc formats and the maximum thickness of the sapphire optical disc in which there will be no significant distortion of the signal due to the high orders spherical aberration of the focused reading beam.

The data show that an increase of numerical aperture $N A$ leads to rapid increasing the value of high order spherical aberrations. It imposes rigorous limitations on the possible thickness of BD format optical disc, which can have the sufficient compensation level of aberrations for optical recording by quartz plate. From data above you can see also that the difference of spherical aberrations for sapphire and polycarbonate discs is

Table 2. Values of spherical aberration for sapphire and polycarbonate layers

\begin{tabular}{|c|c|c|c|c||}
\hline $\begin{array}{c}\text { Type of } \\
\text { media }\end{array}$ & $\lambda$ & $N A$ & $\pm H(\mu \mathrm{m})$ & $\begin{array}{c}\text { The maximum value of } H \text { for which sapphire } \\
\text { can be replaced by polycarbonate }\end{array}$ \\
\hline CD & 780 & 0.45 & 100 & $10 \mathrm{~mm}$ \\
DVD & 650 & 0.6 & 30 & $3 \mathrm{~mm}$ \\
BD & 400 & 0.85 & 3 & $0.3 \mathrm{~mm}$ \\
CD/BD & 400 & 0.26 & 900 & $90.0 \mathrm{~mm}$ \\
\hline
\end{tabular}


V.V.Petrov et al. / Method of aberration compensation...

Table 3. Thickness of sapphire and quartz layers for various formats of the optical discs

\begin{tabular}{|c|c|c|c||}
\hline Type of media & $\begin{array}{c}\text { The thickness of } \\
\text { sapphire substrate } \\
(\mathrm{mm})\end{array}$ & $\begin{array}{c}\text { The thickness of } \\
\text { quartz plate }(\mathrm{mm})\end{array}$ & $\begin{array}{c}\text { Uncompensated } \\
\text { aberration } \Delta \Phi / \Phi_{0}, \\
100 \%\end{array}$ \\
\hline CD & 0.714 & 0.486 & $1 \%$ \\
DVD & 0.357 & 0.243 & $1.6 \%$ \\
CD (for reading at wavelength \\
of $\lambda=400 \mathrm{~nm})$
\end{tabular}

negligible for layer thickness of the standard optical disk and therefore does not impose the additional restrictions on the use of sapphire as a material for the optical disk substrates.

Thus the conditions for obtaining the composite layer (sapphire and quartz layers) with minimal residual aberrations can be written as

$$
\begin{aligned}
& \text { 1) } H_{k v r} / H_{s p f}=0.62 \text { div } 0.72, \\
& \text { 2) } H_{k v r}+H_{s p f}=H_{s u m} \pm 5 \%, \\
& 3)\left|n_{c o m}-n_{s u b}\right|<0.3,
\end{aligned}
$$

where $H_{k v r}$ and $H_{s p f}$ are thicknesses of the quartz and sapphire layers, respectively, $n_{c o m}$ and $n_{\text {sub }}$ are refraction indexes of the compensating plate and disc substrate, respectively. The first condition is condition of the astigmatism compensation (the first term of formula (3)), the second is condition for compensation of spherical aberration of the plane-parallel substrate (the second term of formula (3)), the third is condition for sufficient for optical recording compensation of the higher-order aberrations, $H_{\text {sum }}$ is thickness of the polycarbonate substrate.

Table 3 shows examples of constructional parameters (thickness) of the disc with sapphire substrate and quartz compensating plate for different formats of the optical data storage.

In the case of using the standard optical information reading system the total thickness of quartz compensating plate and the sapphire substrate to be approximately equals (condition 2) the thickness of polycarbonate substrate (due to the broad maximum of spherical aberration at $n_{2}=1.7$ and a symmetrical arrangement relative to the maxima of refractive index of quartz, sapphire, and polycarbonate - Eq. 7). This condition is not rigorous, but it is sufficiently precise for the engineering calculations of the optical system. In principle, the equation (3) can be used to obtain more stringent condition for the spherical aberra-

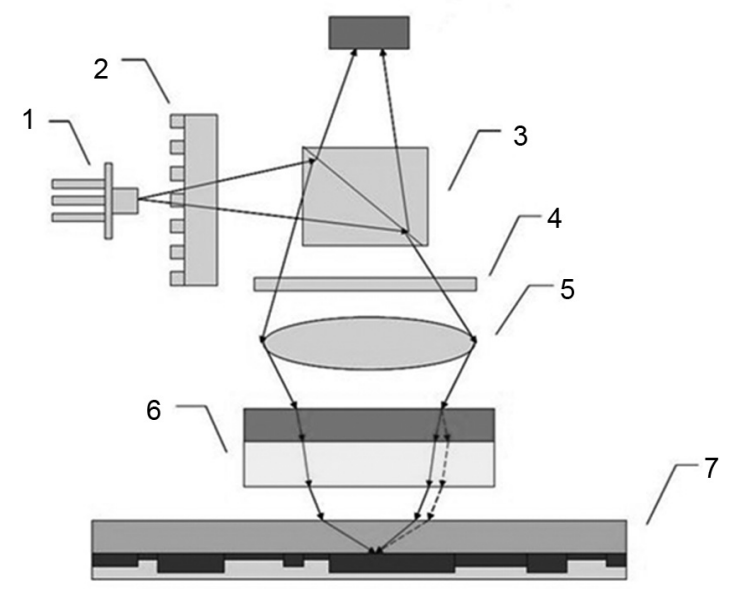

Fig. 5. System of the data reading from the optical medium.

tion compensation. Note that in the case of BD-format the compensating quartz plate is very thin, which can lead to reduced reliability of the data storage on such media and causes the difficulties during its manufacture.

Fig. 5 shows a schematic diagram of the optical system of data reading from optical medium [11]. During data reproducing the laser light is generated by a laser diode (1) through the diffraction grating (2), a quarter-wave plate (4) and beam splitter cube (3) is directed to focusing objective lens (5). The focusing lens focuses the laser beam through compensating plate (6) and medium substrate (7) to the relief structure of information medium. Presence of the single crystal compensating plate leads to the fact that ordinary and extraordinary beams are focused by focusing depth in the one plane.

\section{Experimental results}

Fig. 6 shows the results of the method experimental verification. The pits of CD format were recorded on nickel disc and photo was taken through the sapphire plate with thickness of $1 \mathrm{~mm}$. The images were performing by a microscope having cover glass of $3 \mathrm{~mm}$ and numerical aperture $N A=$ 


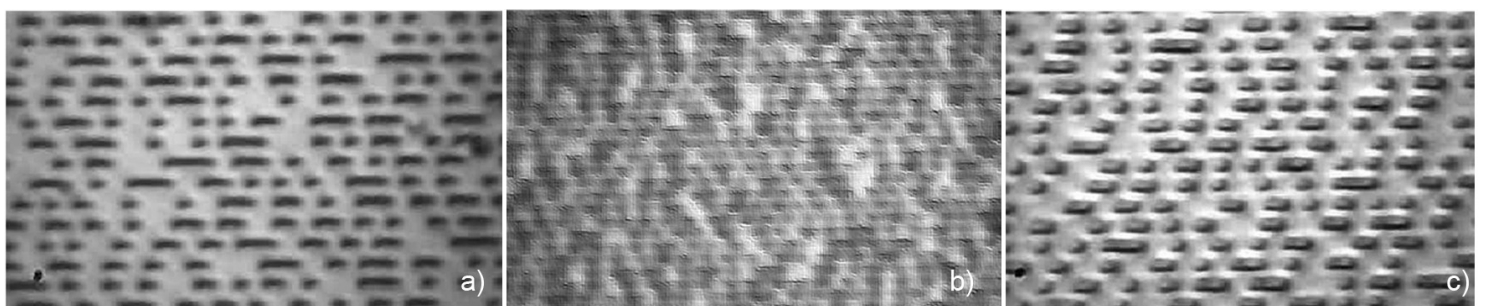

Fig. 6. Images of CD structure through: a) $3 \mathrm{~mm}$ glass plate, b) sapphire substrate without using the quartz compensating plate and c) sapphire substrate using the quartz compensating plate.

0.5. In the first case (Fig. 6a) the image was taken through the $3 \mathrm{~mm}$ glass plate. In the second case (Fig. 6b) sapphire plate was supplemented without compensation of astigmatism and therefore we used a cover glass of thickness $2 \mathrm{~mm}$ to have the total thickness of all plates of $3 \mathrm{~mm}$. In the third case (Fig. 6c) an additional quartz plate with thickness of $0.7 \mathrm{~mm}$ was placed for compensation of astigmatism of the sapphire substrate and therefore the cover glass of thickness $1.3 \mathrm{~mm}$ was used to have the total thickness of all plates of $3 \mathrm{~mm}$.

From Fig. 6 one can see that the image quality through the glass plate and sapphire plate with compensation is almost the same. However in the case of image taking through the sapphire plate without compensation we received a blurred picture with significant distortions.

\section{Conclusions}

Effect of axial birefringence on the propagation of focused laser beam through uniaxial birefringent medium with the vertical optical axis was investigated. The expression for calculating the geometrical aberrations of the focused laser beam in single crystal substrate of the optical disk was obtained.

It was calculated the permissible level of anisotropy for different optical discs formats, the permissible value of thickness for different discs formats and the maximum thickness of the sapphire optical disc in which there will be no significant signal distortion.

The method of aberration compensation for information reading from uniaxial birefringent media with the vertical optical axis was developed. The basic parameters of reading system of sapphire disc with the vertical optical axis were calculated. Constructional parameters (thickness) of the disc with sapphire substrate and quartz compensating plate for the optical disks of different formats are represented.

Experimental verification of the compensation method was performed. It was shown that the image quality through glass plate and sapphire plate with compensation is about the same. The experimental results showed that use of the additional compensating quartz plate allows us performing the information reading from optical sapphire disks.

\section{References}

1. D.E.Nikles, C.E.Forbes, Proc. SPIE, 1499, Accelerated aging studies for polycarbonate optical disk substrates (1991).

2. E.Toppin, Setting a New Standart in Permanent Archival Storage, Digital 2Disc, 42 (2010).

3. Ukrainian Patent No.73611 (2011).

4. J.Vries, D. Schellenberg, L.Abelmann et al., ArXiv.org: 1310.2961v1 (2013).

5. Access point: http://news.sciencemag.org/ sciencenow/2012/07/a-million-year-hard-disk. html [Electronic Resource].

6. J.Zhang, M.Beresna, P.Kazansky, 5D Data Storage by Ultrafast Laser Nanostructuring in Glass (2013).

7. V.V.Petrov, A.A. Kryuchyn, I.V. Gorbov et al., Nanosistemy, Nanomaterialy, Nanotehnologii, 7, 825 (2009).

8. E.R. Dobrovinskaya et al., Sapphire: Material, Manufacturing, Applications, Springer Science + Business Media, Philadelphia (2009).

9. M.Mansuripur, J. Opt.Soc.Am.A, 3, 2086 (1986).

10. S. Stallinga, J.Opt.Soc.Am.A, 18, 2846 (2001).

11. Patent Application No.a201301017 (2013) [in Ukrainian]. 